\title{
Article \\ Evaluating Degradation Coefficients from Existing System Models
}

\author{
Jude A. Osara ${ }^{1, *(1)}$ and Michael D. Bryant ${ }^{2}$ \\ 1 Department of Mechanics of Solids, Surfaces and Systems, Universiteit Twente, \\ 7522 NB Enschede, The Netherlands \\ 2 Mechanical Engineering Department, The University of Texas at Austin, Austin, TX 78712, USA; \\ bryantmd@austin.utexas.edu \\ * Correspondence: j.a.osara@utwente.nl
}

check for

updates

Citation: Osara, J.A.; Bryant, M.D. Evaluating Degradation Coefficients from Existing System Models. Appl. Mech. 2021, 2, 159-173. https:// doi.org/10.3390/applmech2010010

Received: 8 February 2021

Accepted: 9 March 2021

Published: 12 March 2021

Publisher's Note: MDPI stays neutral with regard to jurisdictional claims in published maps and institutional affiliations.

Copyright: (c) 2021 by the authors. Licensee MDPI, Basel, Switzerland. This article is an open access article distributed under the terms and conditions of the Creative Commons Attribution (CC BY) license (https:// creativecommons.org/licenses/by/ $4.0 /)$.

\begin{abstract}
A generalization of the Degradation-Entropy Generation (DEG) theorem to multi-disciplinary multi-physics system-process analysis via a combination with pre-existing system models is presented in this article. Existing models and the DEG methodology are reviewed, and a method for evaluating degradation coefficients $B_{i}$ is proposed. These coefficients characterize the system's transformation based on active dissipative mechanisms, including temperature effects. The consistency of entropy generation in characterizing degradation is then inherited by these often-empirical system models, thereby rendering them more robust and applicable to similar systems without the need for numerous tests and measurements for model corrections. The approach applies to all systems and can quickly analyze and predict a system's performance and degradation, even in the absence of experimental data (using known properties and material constants). Demonstrated applications herein include mechanically loaded systems (frictional wear, grease shearing, fatigue loading), electrochemical energy systems, thermal processes, and others.
\end{abstract}

Keywords: system analysis; degradation; thermodynamics; entropy generation; fatigue; lubricating grease; electrochemical systems; batteries; frictional wear

\section{Introduction}

System characterization models are discipline specific. Formulations are often derived from the natural laws governing the prevalent active interactions using properties that characterize the system and the process. For example, a strain-loaded system is often characterized using the system's strength (or stress $\sigma$ ) and the strain process rate (or strain rate $\dot{\varepsilon}$ ); electrochemical systems are characterized using the system's electrochemical potential (or voltage $E$ ) and the discharge/charge process rate (or current $\dot{q}$ ); tribological systems use friction force $F$ (the product of the system's friction coefficient and normal force, often the system's weight) and interfacial velocity $\dot{x}$; thermal processes use the system's heat capacity $C$ (the product of its mass and specific heat capacity) or thermal conductivity $k$, and the temperature change rate $\dot{T}$ or gradient $\nabla T$ (also the heat transfer rate); and mass transfer processes use the system's pressure $P$, density $\rho$ (or specific volume $v$ ) or concentration and mass flow rate $\dot{m}$. Note that in the above examples, interactions are appropriately described by conjugating system variables with process variables.

Engineers in industry combine time-invariant system response simulations with experimental data to characterize a system. In fields where established simulation tools are not available, statistical analyses and curve fits of measured data are used. A large number of system- and process-specific empirical models are published regularly, which are not applicable to other similar systems when parameters change. Individual manufacturers and laboratories utilize vast research and development resources in characterizing a system, thereby reducing resources available for optimizing or improving the system. In this study, 
existing multi-physics system models are reviewed and combined with the DegradationEntropy Generation DEG theorem [1]. Degradation coefficients are obtained to unify all system analyses consistently via one approach, irrespective of the base model, response parameter or material constant selected for analysis.

\section{Entropy Generation, a Measure of System Degradation}

The consistency of entropy generation in characterizing irreversibilities in systems and processes continues to attract degradation/failure experimentalists from various fields. Recent multi-disciplinary works have shown excellent correlations between entropy-based failure models and experimental measurements [2]. Basaran et al. [3-7] defined damage, via Boltzmann's entropy, as a measure of the change in order/disorder. Using several experimental verifications including solder joints and composites, the authors demonstrated high model-to-experiment correlation. This series of works led to the formulation of the unified mechanics theory [8] which combines a thermodynamic state index with otherwise steady-state physical laws to render them more consistent with experimental observations. Combining thermodynamic laws with damage mechanics, Sosnosvskiy and Sherbakov $[9,10]$ introduced the tribo-fatigue entropy to measure local damage accumulation in a mechanical system. Their approach, termed mechanothermodynamics, includes damage distribution in a volume, correlating well with measurements. Entropy-based works of Khonsari et al. [11-20] have shown consistently accurate characterizations of various mechanical systems under diverse forms of loading, such as grease shearing, metal and composite laminate fatigue as well as interfacial sliding wear. Cuadras et al. [21-23] used entropy generation to estimate damage in resistors, capacitors and batteries, showing consistent correlations between model and measurements. Various works by Bryant et al. [1,24-26] characterizing frictional wear via entropy transfer out of a tribo-control volume led to the formulation of the universally consistent Degradation-Entropy Generation (DEG) theorem [1], which has been shown highly accurate in characterizing real systems undergoing spontaneous degradation often leading to failure. Using several experimental verifications, Osara and Bryant [2,27-30] extended the original DEG theorem to unsteady interactions and nonlinear degradation of multi-component multi-physics system-process interactions including batteries, grease and general fatigue. This article presents a simple, direct and practical approach for evaluating system-characteristic degradation coefficients via a combination of existing system models (theoretical, semi-empirical or empirical) with the minimum entropy generation. The approach is demonstrated for multidisciplinary systems. To keep the discussion herein concise and focused on the primary objective, detailed thermodynamics derivations and discussions are excluded from this article. In the Appendix A, a short summary of relevant foundational irreversible thermodynamics concepts is presented, with several references provided for further reading.

\section{Existing System Characterization Models and Material Constants}

Here we briefly review a few models selected from the literature for diverse engineering systems.

\subsection{Grease}

The rheological properties-thixotropy and viscoelastoplasticity-of grease, a semisolid, make it only partially compliant with Newtonian physics. Manufacturers use inhouse application-dependent half-empirical grease models curve-fitted from hundreds of data sets. NLGI classifications of grease types are given in ranges [31] to provide manufacturers a margin for experimental inconsistencies. Over time, extensive grease research has led to several models describing grease behavior under load. Most of these models are based on very slow shearing of grease at constant temperature, to minimize plastic deformation and strength dissipation, which in turn yields the most consistent experimental correlations. Validity of grease models is often limited to certain operating conditions. Shear stress $\tau$, shear strain rate $\dot{\gamma}$ (also shear rate or strain rate), viscosity $\eta$, penetration, 
thixotropic index and shear modulus $G$ are some commonly used grease characterization parameters and material constants. Table 1 highlights a few grease characterization models for various operational mechanisms.

Table 1. Highlights of a few commonly used grease models.

\begin{tabular}{|c|c|c|c|}
\hline $\begin{array}{l}\text { Operational } \\
\text { Mechanism }\end{array}$ & $\begin{array}{l}\text { Transformation } \\
\text { Measure }\end{array}$ & System Model & Notes \\
\hline \multirow{8}{*}{ Mechanical } & \multirow{5}{*}{$\begin{array}{l}\text { Shear stress } \\
\left.\text { (Yield stress } \tau_{y}\right)\end{array}$} & Power-law: $\tau=K \dot{\gamma}^{n}$ & $\begin{array}{c}\text { Earliest widely adopted model, limited to a narrow range of } \\
\text { medium shear rates [32]. } K \text { is consistency factor and } n \text { is } \\
\text { flow index. }\end{array}$ \\
\hline & & $\begin{array}{l}\text { Herschel-Bulkley: } \\
\qquad \tau=\tau_{y}+K \dot{\gamma}^{n}\end{array}$ & $\begin{array}{l}\text { Currently the most widely used. Good correlation with data at } \\
\text { shear rates between } 0.001 \text { and } 1000 \mathrm{~s}^{-1}[33,34] . n \approx 0.5 \\
\text { for greases. }\end{array}$ \\
\hline & & $\begin{array}{l}\text { Sisko [35]: } \\
\tau=K \dot{\gamma}^{n}+\eta_{h} \dot{\gamma}\end{array}$ & Typically applied to high shear rates $\left(>1000 \mathrm{~s}^{-1}\right)$. \\
\hline & & $\begin{array}{c}\text { Maxwell: } \\
\frac{d \tau}{d t}=G\left(\dot{\gamma}-\frac{\tau}{\eta}\right)\end{array}$ & $\begin{array}{l}\text { Widely used to describe viscoelasticity using a spring in series } \\
\text { with a viscous damper. Gives an accurate time-based shear stress } \\
\text { response at constant shear but does not accurately describe } \\
\text { response to constant shear stress [36]. }\end{array}$ \\
\hline & & $\begin{array}{l}\text { Gecim and Winer [37]: } \\
\qquad \dot{\gamma}= \\
\frac{1}{G_{\infty}} \frac{d \tau}{d t}+\frac{\tau_{L}}{\mu} \tanh ^{-1}\left(\frac{\tau}{\tau_{L}}\right)\end{array}$ & $\begin{array}{l}\text { Adds a nonlinearity to the Newtonian component in the Maxwell } \\
\text { model using the limiting shear stress } \tau_{L} \text { concept [37]. }\end{array}$ \\
\hline & Shear strain & $\begin{array}{l}\text { Kevin-Voigt: } \\
\frac{d \gamma}{d t}=\frac{\tau-\gamma G}{\eta}\end{array}$ & $\begin{array}{l}\text { Connects the spring and damper in parallel and accounts for the } \\
\text { constant shear stress time-dependent strain response. Does not } \\
\text { accurately predict relaxation [36]. }\end{array}$ \\
\hline & & $\begin{array}{c}\text { Mewis [38]: } \\
\frac{d \eta}{d t}=k\left[\eta_{e}\left(\dot{\gamma}_{1}\right)-\eta\right]^{n}\end{array}$ & $\begin{array}{l}\text { Gives rate of change of viscosity at constant shear rate. Constants } \\
\qquad k_{i} \text { are empirically determined. }\end{array}$ \\
\hline & Viscosity & $\begin{array}{c}\text { Cross [39]: } \\
\quad \frac{d N}{d t}= \\
k_{2} P-\left(k_{0}+k_{1} \dot{\gamma}_{1}^{m}\right) N\end{array}$ & $\begin{array}{l}\text { Gives the rate of bond breakdown in grease in terms of number of } \\
\text { linkages } N \text {. The number of links per chain } N \text { is further related } \\
\text { to viscosity. }\end{array}$ \\
\hline \multirow{4}{*}{ Thermal } & Shear stress & $\tau=\gamma_{0} G\left[\exp \left(\frac{E_{a}}{R T}\right)\right]$ & $\begin{array}{l}\text { Uses the Arrhenius formulation to describe grease response to } \\
\text { temperature changes [36]. } E_{a} \text { is activation energy, } R \text { is universal } \\
\text { gas constant. }\end{array}$ \\
\hline & Yield stress & Lugt [32]: & Extends the Arrhenius formulation to yield stress $\tau_{y}$. Constant $b$ \\
\hline & & $\frac{\tau_{y}}{\tau_{y 0}}=\exp \left[\left(\frac{T_{0}-T}{b}\right) \ln 2\right]$ & is empirical. \\
\hline & Viscosity & $\eta=\eta_{0}\left[\exp \left(\frac{E_{a}}{R T}\right)\right]$ & Arrhenius formulation using viscosity. \\
\hline \multirow{3}{*}{ Chemical } & Shear stress & $\begin{array}{c}\text { Osara [2]: } \\
\frac{d \tau}{d t}=\tau_{0} k \exp (-k t)\end{array}$ & $\begin{array}{l}\text { Based on Rhee's [40] } \\
\% \text { degradation }=\mathrm{e}^{-k t}\end{array}$ \\
\hline & Viscosity & $\begin{array}{c}\text { Osara [2]: } \\
\frac{d \eta}{d t}=\eta_{0} k \exp (-k t)\end{array}$ & $\begin{array}{c}\text { Extends Rhee's }[40] \\
\% \text { degradation }=\mathrm{e}^{-k t} \\
\text { to viscosity. }\end{array}$ \\
\hline & Mass & $\begin{array}{c}\text { Lugt [41]: } \\
\frac{d m}{d t}=m_{0} k \exp (-k t)\end{array}$ & $\begin{array}{l}\text { Describes oxidation in grease via mass change. Here, } k \text { is } \\
\text { rate constant. }\end{array}$ \\
\hline
\end{tabular}

In Table 1, the mechanical grease shearing models combine Newtonian, Hookean and power law formulations - the thermal and chemical models are Arrhenian-with experimental measurements. These models are limited to a range of shear rates, grease types and load types, and deviate significantly when applied to uncontrolled grease degradation. Manufacturers apply Table 1 models, and others, with empirical corrections from measured data.

\subsection{Electrochemical Energy Storage}

Energy storage systems such as batteries and capacitors provide portable storage of electrochemical energy. Rechargeable energy storage systems continue to gain significance 
in consumer devices and industrial facilities. Safety and durability issues have plagued the battery industry since the first battery was made, limiting the availability of a battery's energy during operation. Typical battery life is the number of full discharge-charge cycles before available charge content drops below $80 \%$ of initial charge capacity. Battery instability is exacerbated by fast and/or deep cycling. The complex internal kinetics of batteries limit the validity of available characterization models to battery types, configurations and scales. Battery materials researchers and manufacturers rely on voltage-charge curves and Coulomb-counted charge transfer obtained from controlled low-rate cycling, for performance analysis. These are inconsistent when the battery undergoes typical in-operation use-irregular and abusive. Battery models, often empirical, use voltage and charge as characterization parameters. Physics-based models use electrochemical energy. Table 2 reviews a few electrochemical system models or "figures of merit" [42] in the literature. Here, $E$ is voltage, $R$ is resistance, $\dot{q}$ is charge rate or current, $q$ is charge content, $F$ is Faraday's constant and $t$ is time.

Table 2. A review of a few selected electrochemical system models [42].

\begin{tabular}{|c|c|c|}
\hline $\begin{array}{l}\text { Transformation } \\
\text { Measure }\end{array}$ & System Model & Notes \\
\hline Voltage & $E=R \dot{q}$ & $\begin{array}{c}\text { Ohm's law: voltage as a function of current } \\
\text { and resistance. }\end{array}$ \\
\hline Charge content & $q=q_{0} \pm \int_{t_{0}}^{t} \dot{q} d t$ & Charge levels via Coulomb counting. \\
\hline Concentration change & $\Delta c=\frac{\varphi \dot{q} t}{n F E}$ & $\begin{array}{l}\text { Evaluates active species concentration change via } \\
\text { Faraday's electrolysis laws, where } \varphi \text { is current } \\
\text { efficiency, } t \text { is time, } n \text { is number of active species and } \\
F \text { is Faraday's constant. }\end{array}$ \\
\hline Internal resistance & $Z=\frac{E_{O C}-E}{\dot{q}}$ & $\begin{array}{c}\text { A measure of the battery's degradation via its } \\
\text { resistance to charge flow, where } E_{O C} \text { is } \\
\text { open-circuit voltage. }\end{array}$ \\
\hline Fractional conversion & $X_{A}=\frac{m_{0} \pm m}{m_{0}}$ & $\begin{array}{l}\text { Fraction of active species converted during } \\
\text { electrochemical reaction, where } m \text { is amount of } \\
\text { reactant (mass or number of moles). }\end{array}$ \\
\hline $\begin{array}{l}\text { Mass transport } \\
\text { coefficient }\end{array}$ & $k_{L}=\frac{\dot{q}_{L}}{A n F c}$ & $\begin{array}{l}\text { Measures flow / consumption of active species in } \\
\text { electrochemical systems with significant mass } \\
\text { transfer/diffusion, where } \dot{q}_{L} \text { is limiting current, } A \text { is } \\
\text { electrode area and } c \text { is active species concentration. }\end{array}$ \\
\hline
\end{tabular}

\subsection{General Fatigue}

All dynamically loaded non-fluid systems eventually fail. Solids are analyzed using combinations of Newtonian and Hookean mechanics. For metals, which show significant elastic response to certain load magnitudes, steady-state three-dimensional Hookean-based simulations are combined with experimental load-to-failure tests to establish structural integrity under fatigue loading. To avoid unexpected failure due to the inconsistencies in characterization approaches and in situ material response, safety factors are applied during design stages. For high-cycle fatigue (HCF), stress-based approaches such as the stress-life and Modified Goodman curves are used. Components prone to low-cycle fatigue (LCF) are designed using a combination of strain-based models such as Coffin-Manson's strainreversals relation [43] and Morrow's plastic strain energy density [44] with significant safety margins. Table 3 lists a few commonly used fatigue measures $(\sigma=$ stress or strength, $M=$ moment, $M_{t}=$ torque, $I=$ second moment of inertia, $J=$ polar moment of inertia, $\sigma_{f}^{\prime}=$ fatigue strength coefficient, $\varepsilon l_{f}=$ fatigue ductility coefficient, $N=$ number of cycles). 
Table 3. A few commonly used fatigue models $[43,45]$.

\begin{tabular}{|c|c|c|}
\hline $\begin{array}{l}\text { Transformation } \\
\text { Measure }\end{array}$ & System Model & Notes \\
\hline Stress/Strength & $\begin{array}{l}\text { Bending Stress: } \sigma=\frac{M y}{I} \\
\text { Shear Stress: } \tau=\frac{M_{t} y}{J} \\
\text { Fatigue Strength }(\mathrm{HCF}) \\
\qquad \sigma_{N}=\frac{\sigma_{f}^{\prime}{ }^{2}(4 E 6)^{b} N^{b}}{\sigma_{e}} \\
\qquad \sigma_{N}=\sigma_{0}\left(\frac{1+N / N_{e}}{N}\right)^{\alpha}\end{array}$ & $\begin{array}{l}\text { Based on Hookean mechanics, which assumes elastic response to loading. } \\
\text { The fatigue strength }\left(\sigma_{N}\right) \text { equations are obtained from load-to-failure } \\
\text { tests on standard specimens. Special factors are included to account for } \\
\text { materials, surface finishes and other physical aspects of the specimen. } \\
\text { Typically used in high-cycle fatigue analysis. Here, } y \text { is distance, } \sigma_{e} \text { is } \\
\text { endurance strength, } N_{e} \text { is endurance cycle number, and } b \text { and } \alpha \text { are } \\
\text { empirically determined parameters. }\end{array}$ \\
\hline Strain & $\varepsilon_{a}=\frac{\sigma \prime_{f}}{E}\left(2 N_{f}\right)^{b}+\varepsilon_{f}\left(2 N_{f}\right)^{c}$ & $\begin{array}{l}\text { Coffin-Manson equation: empirically determined plastic strain response } \\
\text { to loading, in addition to elastic strain. Typically used for low-cycle } \\
\text { fatigue, where } b \text { and } c \text { are evaluated from empirical load-to-failure data. } \\
\qquad N_{f} \text { is number of cycles to failure. }\end{array}$ \\
\hline CDM Damage & $D=\frac{-D_{N_{f}-1}}{\ln N_{f}} \ln \left[1-\frac{N}{N_{f}}\right]$ & $\begin{array}{l}\text { Based on Continuum Damage Mechanics, the damage variable } D \\
\text { predicts a logarithmic load-to-failure response [45]. }\end{array}$ \\
\hline Fracture rate & $\frac{d a}{d N}=C\left(\Delta K_{1}\right)^{m}$ & $\begin{array}{l}\text { Paris law for predicting crack growth, where } a \text { is crack length, } \Delta K_{1} \text { is } \\
\text { stress intensity range per cycle, } C \text { and } m \text { are empirical material constants. }\end{array}$ \\
\hline
\end{tabular}

Fatigue models in Table 3 are either steady-state physics-based or load-to-failure empirical [43]. Their correlations with actual in-operation data are inconsistent, requiring significant corrections and safety factors. Highly conservative design (or over-designing), which wastes resources, is often an undesired result of using these approaches.

\section{The Degradation-Entropy Generation (DEG) Theorem}

Bryant et al. [1], following a series of experimental studies of friction wear, proposed the Degradation-Entropy Generation DEG theorem which linearly correlates a degradation measure $w$ and entropy generation $S_{i}^{\prime}$. Mathematically,

$$
\stackrel{\prime}{w}=\sum_{i} B_{i} \dot{S}_{i}^{\prime}
$$

where degradation/transformation coefficients $B_{i}=\left.\frac{\partial w}{\partial S^{\prime}{ }_{i}}\right|_{p_{i}}$ are obtained as slopes of degradation measure $\mathrm{w}$, with respect to entropy generations $S^{\prime}{ }_{i}$; the $\mid p_{i}$ notation indicates active processes $p_{i}$ numbered by index $i$. Details of the DEG theorem, including statements and proof, can be found in [1]. Frictional wear [1,24-26] and fatigue [11-17] experiments verified the theorem. A breakdown of entropy generation can be found in this article's Appendix A. Osara and Bryant [2,27-30], via a combination of Equations (A3) and (A4) (see Appendix A) with Equation (1), instantaneously characterized unsteadily loaded multicomponent multi-physics systems, with verification using measured data from grease aging, lithium-ion battery and lead-acid battery degradation, and general fatigue experiments.

\subsection{DEG Methodology Procedure}

Bryant et al. proposed a structured approach for applying the DEG theorem to degradation analysis: identify and measure the degradation measure $w$ and active process energies $p_{i}$ (or powers); evaluate entropy generation $S_{i}^{\prime}=S_{i}^{\prime}\left(p_{i}\right)$ caused by the $p_{i}$; relate degradation measure to entropy generation terms to obtain transformation coefficients. When measurements are available, the extended approach for instantaneous analysis by Osara and Bryant, presented in recent publications [2,27-30], is recommended. With entropy defined as the quotient of energy and temperature, the DEG approach subsumes temperature effects.

\subsection{DEG Coefficients}

DEG coefficients $B_{i}$ show the system's natural response to active dissipative processes and conditions by estimating the processes' contributions towards system degradation 
and eventual failure. For monotonically aging systems, e.g., a solid under low-cycle fatigue loading, DEG coefficients from the first few time steps predict the system's normal operating path, and can be used for instantaneous health monitoring and failure detection. In non-reactive systems, load-to-failure DEG coefficients from a representative sample of the system can characterize other systems of the same composition undergoing similar processes in operation. In secondary (rechargeable) energy systems, DEG coefficients obtained from the first few cycles predict subsequent cycles to failure. Evaluating the $B_{i}$ from Equation (1) indicates a high entropy generation rate yields a low $B_{i}$ for a given transformation rate. Hence a high $B_{i}$ (for primary interactions) is favorable to system transformation. This article combines the DEG theorem with existing system-specific models to obtain characteristic DEG coefficients.

\section{A Brief Review of Existing DEG Models}

The DEG theorem is general and about the dynamics of loss and dissipation. The theorem renders the differential equations governing any loss or dissipative process, including material degradation and processes that dissipate energy, such as battery discharge and flow disruption. Several experimental studies have applied the DEG theorem to multiphysics systems undergoing steady, unsteady and abusive loadings with results yielding characteristic DEG coefficients.

\subsection{Frictional Wear}

Characterization of material wear occurring at a dynamic tribological interface is one of the earliest applications of the DEG theorem [1,24-26]. Relating measured wear volume to entropy transfer out of the interface (obtained from temperature-only measurements)

$$
w_{v}=B_{W} \frac{Q}{T}
$$

Bryant et al. obtained the wear-characteristic DEG coefficient. Here, $Q$ is heat transfer into/out of the tribo-control volume.

\subsection{Grease}

Osara and Bryant, applying the DEG theorem to grease degradation, obtained the shear stress-based relationship [27]

$$
\int_{t_{0}}^{t} \tau d t=B_{\mu T} \int_{t_{0}}^{t}-\left(\rho \ln T+\frac{\alpha}{\kappa_{T}} \gamma\right) \frac{\dot{T}}{T} d t+B_{W} \int_{t_{0}}^{t}-\frac{\tau \dot{\gamma}}{T} d t
$$

Data from mechanical shearing of two grease types yielded DEG coefficients $B_{\mu T}=$ $-0.504 \mathrm{~Pa}-\mathrm{S} \mathrm{K} / \mathrm{J}$ and $B_{W}=-10.36 \mathrm{~Pa}-\mathrm{S} \mathrm{K} / \mathrm{J}$ (NLGI 4 grease), and $B_{\mu T}=-0.031 \mathrm{~Pa}-\mathrm{s} \mathrm{K} / \mathrm{J}$ and $B_{W}=-10.38$ Pa-s K/J (NLGI 2 grease), obtained using strain rate-controlled grease shearing. In Equation (3), $\rho$ is density, $c$ is specific heat capacity, $\alpha$ is thermal expansion coefficient, $\kappa_{T}$ is isothermal shearability (the inverse of the shear modulus $G$ ) and other variables are as defined previously.

\subsection{Electrochemical Energy Storage Systems}

Measurements from abusive cycling of several $6 \mathrm{~V}$ lead-acid and $3.7 \mathrm{~V}$ lithium-ion batteries verified the DEG battery model given as $[28,30]$

$$
q=\int_{t_{0}}^{t} \dot{q} d t=B_{V T} \int_{t_{0}}^{t} \frac{q \dot{E}}{T} d t+B_{W} \int_{t_{0}}^{t} \frac{E \dot{q}}{T} d t
$$

where variables are as defined previously. Degradation coefficients obtained from battery discharge data are $B_{V T}=13.8 \mathrm{Ah} \mathrm{K} / \mathrm{Wh}$ and $B_{W}=51.9 \mathrm{Ah} \mathrm{K} / \mathrm{Wh}$ for lead-acid batteries; and $B_{V T}=113 \mathrm{Ah} \mathrm{K} / \mathrm{Wh}$ and $B_{W}=76.6 \mathrm{Ah} \mathrm{K} / \mathrm{Wh}$ for lithium-ion batteries. 


\subsection{General Fatigue}

Application of the DEG methods to fatigue yielded the strain-based model (for stresscontrolled loading) [29]

$$
\varepsilon=\int_{t_{0}}^{t} \dot{\varepsilon} d t=B_{\mu T} S_{\mu T}+B_{W} S_{W}
$$

where microstructurothermal (MST) entropy $S_{\mu T}=-\int_{t_{0}}^{t}\left(\rho c \ln T+\frac{\varepsilon \alpha}{\kappa_{T}}\right) \frac{\dot{T}}{T} d t$ and load entropy $S_{W}=-\int_{t_{0}}^{t} N_{d t} \frac{\sigma_{N}}{T}:\left[\dot{\varepsilon}_{e N}+\left(\frac{1-n^{\prime}}{1+n^{\prime}}\right) \dot{\varepsilon}_{p N}\right] d t$. For very high-cycle fatigue and infinite life, assuming elastic (and isothermal) load, Equation (5) reduces to

$$
\varepsilon=B_{W} \frac{\sigma_{N}}{T} \varepsilon_{e} .
$$

For strain-controlled loading, stress response may be used as transformation measure. Data measured during low-cycle fatigue of a stainless-steel specimen SS 304 yielded DEG coefficients $B_{\mu T}=0.22$ (bending) and 0.42 (torsion); and $B_{W}=-0.92$ (bending) and -1.96 (torsion).

\subsection{Combined Adhesive and Abrasive Wear}

Lijesh and Khonsari [19] presented a DEG model characterizing multiple wear modes. Combining frictional entropy generation-from frictional force $F$ and velocity $\dot{x}$-with measured volumetric wear rate

$$
w_{v}=B_{1} \int_{t_{0}}^{t_{1}} \frac{F_{1} \dot{x}_{1}}{T_{1}}+B_{2} \int_{t_{1}}^{t_{2}} \frac{F_{2} \dot{x}_{2}}{T_{2}}+B_{3} \int_{t_{2}}^{t_{3}} \frac{F_{3} \dot{x}_{3}}{T_{3}}
$$

the authors obtained degradation coefficients from data measured on a tribometer with a stationary pin on a rotating disk: $B_{1}=0.422 \mathrm{~mm}^{3} \mathrm{~K} / \mathrm{J}$ (for adhesion wear mode), $B_{2}=0.436$ $\mathrm{mm}^{3} \mathrm{~K} / \mathrm{J}$ (for transition wear, an unsteady process) and $B_{3}=0.464 \mathrm{~mm}^{3} \mathrm{~K} / \mathrm{J}$ (for abrasion wear) for the three wear regions identified.

\section{Degradation Coefficients from a Combination of the DEG Models and Other Existing Multi-Physics Models}

To use the system-specific models in Section 2 (Tables 1-3), researchers and industry engineers have to adhere to strict assumptions, use specialized equipment and test several samples of the component or system. Since all systems dissipate energy which generates entropy during loading, a combination of the DEG theorem with an established system-specific governing equation can yield degradation coefficients that consistently characterize the systems. Simple or in situ measurements can then be used to evaluate entropy generated by the active processes. A concise discussion of entropy generation is presented in the Appendix A. Table A1 lists minimum (or pseudo-steady) entropy generation equations for various system-process interactions. In the absence of measurement capabilities, existing data in the literature can also be used to estimate values for a system's degradation coefficients.

For solid interfacial wear due to sliding friction governed by Coulomb's friction law $F=\eta N$ and Archard's wear law $\dot{w}=k N \dot{x} / H$, minimum entropy generation rate, from Equation (A1) with $X=F$ and $\dot{J}=\dot{x}$, is $\dot{S}_{\text {min }}=\eta N \dot{x} / T$. Via the DEG theorem, Equation (1), wear rate $\dot{w}=B \eta N \dot{x} / T$ which, via comparison with Archard's wear law, yields degradation coefficient $B=k T / \eta H$. Here, $k$ is wear constant, $T$ is temperature, $\mu$ is friction coefficient, $H$ is the hardness of the softer material and $\dot{x}$ is interfacial sliding velocity. Doelling et al., using an experimentally measured $B$, obtained a value of Archard's wear constant $k$ similar to that obtained by Rabinowicz. This procedure can be applied to all and sundry systems, as demonstrated in the subsequent sub-sections for the previously reviewed systems. 


\subsection{Grease}

Steady entropy generation rate due to mechanical shearing of grease, Table A1, is $\dot{S} \prime_{\min }=V \tau \dot{\gamma} / T$ and for chemical degradation, $\dot{S} \prime_{\min }=\frac{\mu \dot{m}}{M_{M} T}$. Thermal entropy rate due to temperature change, a transient phenomenon, is $\dot{S}=C \dot{T} / T$. V is volume, $\tau$ is shear stress, $\dot{\gamma}$ is shear strain rate, T is temperature, $\mu$ is chemical potential, $\dot{m}$ is mass flow rate, $M_{M}$ is molecular mass and $C$ is heat capacity. Presented in Table 4 are combinations of various system models (column 3) with DEG models (column 4) to yield degradation coefficients (column 5), as done for interfacial wear in the previous paragraph. In Table 4, Pen = penetration depth; see definitions of other variables in Table 1.

Table 4. Degradation coefficients from existing grease models reviewed in Table 1.

\begin{tabular}{|c|c|c|c|c|}
\hline Mechanism & Measure & System Model & DEG Model & Degradation Coefficient \\
\hline \multirow{6}{*}{ Mechanical } & Shear stress & $\begin{array}{c}\text { Maxwell: } \\
\frac{d \tau}{d t}=G\left(\dot{\gamma}-\frac{\tau}{\eta}\right)\end{array}$ & $\frac{d \tau}{d t}=B \frac{V \tau \dot{\gamma}}{T}$ & $B=\frac{T G}{V \tau \dot{\gamma}}\left(\dot{\gamma}-\frac{\tau}{\eta}\right)$ \\
\hline & Shear strain & $\begin{array}{l}\text { Kevin-Voigt: } \\
\frac{d \gamma}{d t}=\frac{\tau-\gamma G}{\eta}\end{array}$ & $\frac{d \gamma}{d t}=B \frac{V \tau \dot{\gamma}}{T}$ & $B=\frac{T}{V \tau \dot{\gamma} \eta}(\tau-\gamma G)$ \\
\hline & Viscosity & $\begin{array}{c}\text { Mewis: } \\
\begin{aligned} \frac{d \eta}{d t} & =k\left[\eta_{e}\left(\dot{\gamma}_{1}\right)-\eta\right]^{n} \\
\text { Cross: } \frac{d N}{d t}= & =k_{2} P-\left(k_{0}+k_{1} \dot{\gamma}_{1}{ }^{m}\right) N\end{aligned}\end{array}$ & $\frac{d \eta}{d t}=B \frac{V \tau \dot{\gamma}}{T}$ & $\begin{array}{c}B=\frac{k T\left[\eta_{e}-\eta\right]^{n}}{V \tau \dot{\gamma}} \\
B=\frac{T\left[k_{2} P-\left(k_{0}+k_{1} \dot{\gamma}^{m}\right) N\right]}{V \tau \dot{\gamma}}\end{array}$ \\
\hline & Yield stress & $\begin{array}{c}\text { H-B: } \tau=\tau_{y}+K \dot{\gamma}^{n} \\
\tau_{y}=3 E 10 * \operatorname{Pen}^{-3.17}\end{array}$ & $\tau=B \frac{V \dot{\gamma} \int_{t_{N}} \tau d t}{T}$ & $B=\frac{T\left(\tau_{y}+K \dot{\gamma}^{n}\right)}{V \dot{\gamma} \int_{t_{N}} \tau d t}$ \\
\hline & Consistency & $\operatorname{Pen}=\left(32.5 * 10^{31.7} \tau_{y}^{-0.315}\right)$ & $P e n=B \frac{V \dot{\gamma} \int_{t_{N}} \tau d t}{T}$ & $B=\frac{T\left(32.5 * 10^{31.7} \tau_{y}-0.315\right)}{V \dot{\gamma} \int_{t_{N}} \tau d t}$ \\
\hline & $\begin{array}{l}\text { Thixotropic } \\
\text { Index }\end{array}$ & $T I=\frac{\eta_{s}}{\eta_{10 s}}=\frac{10(\tau-\gamma G)_{s}}{(\tau-\gamma G)_{10 s}}$ & $T I=B \frac{V \dot{\gamma} \int_{t_{N}} \tau d t}{T}$ & $B=\frac{10 T \tau_{s}}{\dot{\gamma}_{V} \tau_{10 s} \int_{t_{N}} \tau}$ \\
\hline \multirow{2}{*}{ Thermal } & Yield stress & $\frac{\tau_{y}}{\tau_{y 0}}=\exp \left[\left(\frac{T_{0}-T}{b}\right) \ln 2\right]$ & $\tau_{y}=B C \ln \left[\frac{T}{T_{0}}\right]$ & $B_{T}=\frac{\tau_{y 0} \exp \left[\frac{T_{0}-T}{b} \ln 2\right]}{\operatorname{Cln}\left[T / T_{0}\right]}$ \\
\hline & Viscosity & $\eta=\eta_{0}\left[\exp \left(\frac{E_{a}}{R T}\right)\right]$ & $\eta=B C \ln \left[\frac{T}{T_{0}}\right]$ & $B_{T}=\frac{\eta_{0}\left[\exp \left(\frac{E_{T}}{R T}\right)\right]}{\operatorname{Cln}\left[T / T_{0}\right]}$ \\
\hline \multirow{3}{*}{ Chemical } & Shear stress & $\frac{d \tau}{d t}=\tau_{0} k \exp (-k t)$ & $\frac{d \tau}{d t}=B \frac{\mu \dot{m}}{M_{M} T}$ & $B_{m}=\frac{\tau_{0} k M_{M} \operatorname{Texp}(-k t)}{\mu \dot{m}}$ \\
\hline & Viscosity & $\frac{d \eta}{d t}=\eta_{0} k \exp (-k t)$ & $\frac{d \eta}{d t}=B \frac{\mu \dot{m}}{M_{M} T}$ & $B_{m}=\frac{\eta_{0} k M_{M} \operatorname{Texp}(-k t)}{\mu \dot{m}}$ \\
\hline & Mass & $\frac{d m}{d t}=m_{0} k \exp (-k t)$ & $\frac{d m}{d t}=B \frac{\mu m}{M_{M} T}$ & $B_{m}=\frac{m_{0} k M_{M} \operatorname{Texp}(-k t)}{\mu \dot{m}}$ \\
\hline
\end{tabular}

\subsection{Electrochemical Energy Storage Systems}

For a battery or other electrochemical energy device governed by Ohm's law $E=$ $R \dot{q}$, minimum entropy generation rate is $S_{\text {min }}^{\prime}=E \dot{q} t / T$. Thermal entropy rate due to temperature change only is $\dot{S}=C \dot{T} / T$. Table 5 presents previously reviewed battery models (in column 2) which are directly compared (equated) to DEG models (in column 3) to yield degradation coefficients (column 4). 
Table 5. Degradation coefficients from existing electrochemical energy storage models reviewed in Table 2.

\begin{tabular}{cccc}
\hline Measure & System Model & DEG Model & Degradation Coefficient \\
\hline Voltage & $E=R \dot{q}$ & $\frac{d E}{d t}=B \frac{E \dot{q}}{T}$ & $B=\frac{T}{q}$ \\
Charge content & $q=\int_{t_{0}}^{t} \dot{q} d t$ & $q=B \int_{t_{0}}^{t} \frac{E \dot{q}}{T} d t$ & $B=\frac{T}{E}$ \\
Concentration change & $\Delta c=\frac{\varphi \dot{q} t}{n F E}$ & $\Delta c=B \frac{E \dot{q} t}{T}$ & $B=\frac{T \varphi}{n F E^{2}}$ \\
Internal resistance & $Z=\frac{E_{O C}-E}{\dot{q}}$ & $X_{A}=B \frac{E \frac{E \dot{q}}{T}}{E \dot{q}^{2}}$ & $B=\frac{T\left(E_{O C}\right.}{m_{0}}$ \\
Fractional conversion & $X_{A}=\frac{m_{0} \pm m}{m_{0}}$ & $k_{L}=B \frac{E \dot{q}}{T}$ & $B=\frac{T\left(m_{0} \pm m\right)}{E \dot{q} m_{0}}$ \\
Mass transport coefficient & $k_{L}=\frac{\dot{q}_{L}}{A n F c}$ & $B=\frac{T \dot{q}_{L}}{E \dot{q} A n F c}$ \\
\hline
\end{tabular}

\subsection{General Fatigue}

Similar to grease, a semi-solid, mechanically loaded solid materials, via stress $\sigma$ and cyclic strain amplitude $\dot{\varepsilon}$, generate steady-state entropy at rate $\dot{S}_{\prime \min }=\sigma: \dot{\varepsilon} / T$ and for chemical degradation including metal rust, $\dot{S} \prime_{\min }=\frac{\mu \dot{m}}{M_{M} T}$. Thermal entropy rate due to temperature change is $\dot{S}=C \dot{T} / T$. In the absence of measured stress and strain, empirical relations can be used to estimate entropy generation. For steels, combining elastic energy $W_{e}$ with Morrow's cyclic plastic strain energy $W_{p}$ gives $\dot{S}_{\text {min }}=\dot{W} / T=\left(\dot{W}_{e}+\dot{W}_{p}\right) / T=$ $\frac{\sigma_{N}}{T}:\left[\varepsilon_{e N}+\varepsilon_{p N}\left(\frac{1-n \prime}{1+n \prime}\right)\right]$, where the subscript $N$ denotes cyclic. In Table 6 , previously reviewed fatigue models (column 2) are combined with DEG models (column 3) to obtain degradation coefficients (column 4).

Table 6. Degradation coefficients from existing fatigue models reviewed in Table 3. Note the logarithmic entropy generation $\ln \left[1-\frac{S{ }^{\prime}}{S{ }^{\prime} W_{f}}\right]$ derived for CDM damage [2] where load entropy $S{ }^{\prime} W=\dot{W} / T$ and $S{ }^{\prime} W_{f}$ is the value at failure.

\begin{tabular}{|c|c|c|c|}
\hline Measure & System Model & DEG Model & Degradation Coefficient \\
\hline Stress/Strength & $\begin{array}{c}\sigma=\frac{M y}{J} \\
\tau=\frac{M_{t} y}{J} \\
\sigma_{N}=\frac{\sigma_{f}^{\prime}(4 E 6)^{b} N^{b}}{\sigma_{e}} \\
\sigma_{N}=\sigma_{0}\left(\frac{1+N / N_{e}}{N}\right)^{\alpha}\end{array}$ & $\begin{array}{c}\sigma=B \frac{\sigma: \dot{\varepsilon}}{T} \\
\tau=B \frac{\tau: \dot{\gamma}}{T} \\
\sigma_{N}=B_{W} \frac{\sigma_{f}^{\prime}: \varepsilon}{T}\end{array}$ & $\begin{array}{c}B_{W_{\sigma}}=\frac{M y T}{I \sigma \dot{\varepsilon}} \\
B_{W_{\tau}}=\frac{M_{t} y T}{J \tau \dot{\gamma}} \\
B_{W N}=\frac{\sigma_{f^{2}(4 E 6)^{b} N^{b}}^{\sigma_{e}} /\left[\frac{\sigma_{f}^{\prime}: \varepsilon}{T}\right]}{B_{W_{N}}=} \\
{\left[\sigma_{0}\left(\frac{1+N / N_{e}}{N}\right)^{\alpha}\right] /\left[\frac{\sigma_{f}^{\prime}: \varepsilon}{T}\right]}\end{array}$ \\
\hline Strain & $\varepsilon_{a}=\frac{\sigma \prime_{f}}{E}\left(2 N_{f}\right)^{b}+\varepsilon_{f}\left(2 N_{f}\right)^{c}$ & $\varepsilon_{a}=B_{W_{N}} \int_{N_{0}}^{N_{l c f}} \frac{\dot{W}}{T} d N$ & $B_{W_{N}}=\frac{\frac{\sigma_{f}}{E}\left(2 N_{f}\right)^{b}+\varepsilon l_{f}\left(2 N_{f}\right)^{c}}{\int_{N h}^{N_{l c f}} \frac{\dot{\omega}}{T} d N}$ \\
\hline CDM Damage & $D=\frac{-D_{N_{f}-1}}{\ln N_{f}} \ln \left[1-\frac{N}{N_{f}}\right]$ & $D=B_{W_{D}} \ln \left[1-\frac{S{ }_{W}}{S{ }^{\prime} W_{f}}\right]$ & $B_{W_{D}}=-\frac{D_{N_{f}-1}}{\ln N_{f}}$ \\
\hline Fracture rate & $\frac{d a}{d N}=C\left(\Delta K_{1}\right)^{m}$ & $\frac{d a}{d N}=B \frac{\left(G-2 \gamma_{0}\right) \dot{J}}{T}$ & $B=\frac{T C\left(\Delta K_{1}\right)^{m}}{\left(G-2 \gamma_{0}\right) \dot{J}}$ \\
\hline
\end{tabular}

In Tables 4-6, a consistent approach for obtaining DEG coefficients from existing system models was demonstrated for variegated multi-physics system transformations. The degradation coefficients can then be used to predict aging/degradation behavior and trajectory of the system as done in prior DEG publications.

\subsection{High-Rate Processes and Multiple Simultaneous Dissipation Mechanisms}

High-rate mechanical, electrical and chemical processes generate heat in the system which, in turn, raises the system's temperature. For such systems and others undergoing multiple energy transformations, the DEG theorem suggests degradation is determined from the sum of the individual contributions of all the active transformations. For materials undergoing high-rate processes accompanied by temperature rise, a thermal model should be added to the primary process model. However, for relatively steady processes 
or slow to average-speed processes, individual models in Tables 4-6 apply adequately and consistently.

For systems undergoing multiple concurrent interactions, a degradation coefficient is obtained for each interaction. Combined, total degradation due to simultaneously active processes is

$$
\dot{w}=B_{1} \dot{S}_{1}^{\prime}+B_{2} \dot{S}_{2}^{\prime}+\ldots+B_{i} \dot{S}_{i}^{\prime}
$$

where $i$ indexes active interactions. This renders a degradation model-which can be calibrated via pre-existing models--that weighs influence of energy changes due to individual dissipative processes. Substituting the degradation coefficients from the viscosity rows of Table 4 into Equation (8) — selecting the Mewis model for mechanical-yields total rate of degradation due to mechanical, chemical and thermal mechanisms, gauged with viscosity

$$
\frac{d \eta}{d t}=\left[\frac{\eta_{0}\left[\exp \left(\frac{E_{a}}{R T}\right)\right]}{\ln \left(T / T_{0}\right)}\right] \frac{\dot{T}(t)}{T(t)}+\left[\frac{k T\left(\eta_{e}-\eta\right)^{n}}{\tau}\right] \frac{\tau(t)}{T(t)}+\left[\frac{-\eta_{0} k M_{M} T \exp (-k t)}{\dot{m}}\right] \frac{\dot{m}(t)}{T(t)}
$$

where constants $C, \dot{\gamma}_{V}$ and $\mu$ divide out. Similarly, total degradation rate via shear stress, using the Maxwell model for mechanical, is

$$
\frac{d \tau}{d t}=\left[\frac{\tau_{y 0} \exp \left[\frac{T_{0}-T}{b} \ln 2\right]}{\ln \left[T / T_{0}\right]}\right] \frac{\dot{T}(t)}{T(t)}+\left[\frac{T G}{\tau}\left(\dot{\gamma}-\frac{\tau}{\eta}\right)\right] \frac{\tau(t)}{T(t)}+\left[\frac{-\tau_{0} k M_{M} T \exp (-k t)}{\dot{m}}\right] \frac{\dot{m}(t)}{T(t)}
$$

The terms in square brackets can be evaluated from known properties or models of grease, or measured on samples. The coefficients determine the significance of individual dissipative processes and can be used in in situ optimization. In Equations (9) and (10), only changing values of temperature, shear stress and mass need be monitored to determine degradation rate.

\subsection{Unsteady Interactions}

Processes with significant fluctuations render steady-state or single-process models in Tables 1-3 often inadequate for system characterization, introducing errors and inconsistency of results. As anticipated, obtained DEG coefficients will inherit the inconsistencies associated with the extent of invalidity/deviation of the used model from the actual process. For such highly unsteady interactions, which typically do not have established system models, a more detailed thermodynamic analysis employing the free energies (see Equations (A3) and (A4) in the Appendix A) was presented by the authors in recent publications (references [2,27-30]).

\section{Summary and Conclusions}

In this study, the universal and direct applicability of the Degradation-Entropy Generation DEG theorem to interdisciplinary multi-physics system degradation analysis was demonstrated. Degradation coefficients $B_{i}$ were obtained via a combination of the DEG theorem with pre-existing system-specific models. The proposed method was applied to several grease, battery and fatigue models. Using measured or existing data in the literature, system transformation/degradation behavior can be readily characterized for diagnostic and prognostic analysis.

Author Contributions: Conceptualization, J.A.O. and M.D.B.; Data curation, J.A.O.; Formal analysis, J.A.O.; Investigation, J.A.O.; Methodology, J.A.O. and M.D.B.; Resources, J.A.O.; Software, J.A.O.; Validation, J.A.O.; Writing-original draft, J.A.O.; Writing-review and editing, J.A.O. and M.D.B. All authors have read and agreed to the published version of the manuscript.

Funding: This research received no external funding.

Conflicts of Interest: The authors declare no conflict of interest. 


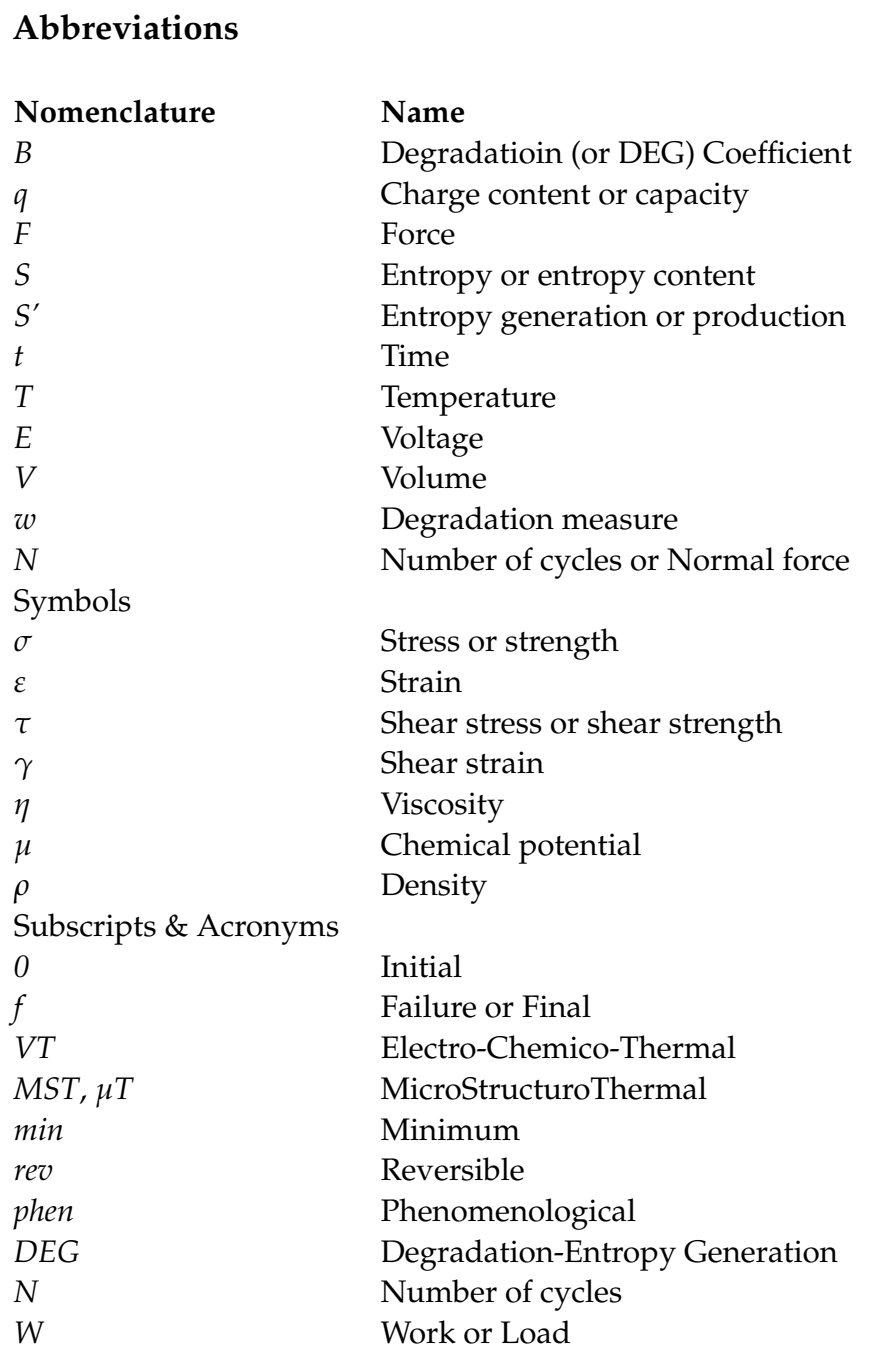

\section{Appendix A. Entropy Generation in Active Systems}

In this section, we concisely review relevant irreversible thermodynamics concepts, from Prigogine's minimum entropy generation (Equation (A1)) and variation of entropy generation (Equation (A2)) to Osara and Bryant's phenomenological entropy generation rate (Equations (A3) and (A4)). To keep this article focused on the discussion in the main body, this Appendix A excludes detailed discussions of thermodynamics which are beyond the current scope. This paper's primary goal is to present a quick, practical and easy-to-adopt combination of entropy with existing models via the DEG theorem. We recommend to the interested reader references $[2,27-30]$ for more on detailed derivations and breakdowns.

\section{Appendix A.1. The Single-Variable System and Minimum Entropy Generation}

System-process properties (or variables) often conjugate in pairs to define the system's power, e.g., $\sigma \dot{\varepsilon}, E \dot{q}, F \dot{x}, C \dot{T}, k \nabla T$, Pvim define mechanical, electrochemical, frictional/dynamic, thermal (heat storage and transfer) and flow powers, respectively. Power and energy formulations define macro transformations of systems between equilibrium states, hence are reversible. Real systems, undergoing non-equilibrium transformations, are irreversible. Theory and experiments have long established that the accuracy of energy formulations in real system characterization is higher at slow process rates: a quasi-static (very slow or nearly stationary) system is quasi-reversible. For example, cycling a battery at a high rate generates internal heat at a high rate, rendering power $E \dot{q}$ inadequate for full characterization of the battery's transformation. This is similarly observed in other systems whose 
models require temperature correction or isothermal conditions in experiments. However, many systems operate long enough to asymptotically approach steady state, during which temperature variation is minimal and therefore, negligible. Such a system undergoing a single predominant process is termed a single-variable system [1]. For example, steel fatigue measurements by Naderi and Khonsari [12,15] showed a pseudo-steady temperature region for most of the sample's fatigue life, prior to failure. Via temperature control, Bryant et al. [1] adequately characterized a frictional process using only the frictional work.

To measure the internal material disorganization that accompanies energy transformation in real systems, the second law introduces entropy. Generalizing Clausius' entropy - the quotient of heat transfer and temperature - to all systems, seminal works by Rayleigh, Onsager and Prigogine defined a system's minimum entropy generation rate as the quotient of power and temperature. Mathematically [46-48],

$$
\dot{S}_{\min }^{\prime}=\frac{X \dot{J}}{T}
$$

where $X$ is generalized force (or potential), $\dot{J}$ is generalized flow rate, $T$ is temperature, and $X / T$ is termed the thermodynamic force. The dot notation represents time rate of change. Equation (A1) applies to single-variable systems-systems that are minimally perturbed from equilibrium, defining the minimum condition (reference limit) for any real system to exist in nature, also known as the stationary non-equilibrium state $[46,48]$. The single-variable system, a pseudo steady-state system-process interaction, generates minimal entropy. Table A1 lists minimum entropy generation rate equations for various multi-physics systems.

Table A1. Steady-state or minimum entropy generation rate for multi-physics active dissipative processes.

\begin{tabular}{cc}
\hline Mechanism & Minimum Entropy Generation \\
\hline Solid Interfacial Sliding-Friction & $\dot{S}_{\text {min }}^{\prime}=\frac{\eta N \dot{x}}{T}$ \\
Battery Cycling & $\dot{S}_{\min }^{\prime}=\frac{E \dot{q}}{T}$ \\
Heat Transfer & $\dot{S}_{\min }^{\prime}=Q\left(\frac{1}{T_{2}}-\frac{1}{T_{1}}\right)$ \\
Lubricant Shearing & $\dot{S}_{\min }^{\prime}=\frac{V \tau \dot{\gamma}}{T}$ \\
Diffusion & $\dot{S}_{\text {min }}^{\prime}=\frac{\left(\mu_{\text {high }}-\mu_{\text {low }}\right) \dot{N}}{T}$ \\
Abrasion/Cutting & $\dot{S}_{\min }^{\prime}=\frac{F \dot{x}_{c}}{T}$ \\
Reactions (Chemical, Nuclear, etc.) & $\dot{S}_{\text {min }}^{\prime}=\frac{\mu \dot{m}}{M_{M} T}$ \\
Stress/Fatigue Loading & $\dot{S}_{\min }^{\prime}=\frac{V \sigma \dot{\varepsilon}}{T}$ \\
Fracture & $\dot{S}_{\min }^{\prime}=\frac{\left(G-2 \gamma_{0}\right) \dot{J}}{T}$ \\
\hline
\end{tabular}

Appendix A.2. The Thermodynamic Simple System and Phenomenological Entropy Generation

According to the thermodynamic state postulate [47,49-51], the state of a simple system is completely specified by $r+1$ independent intensive properties where $r$ is the number of prevalent work interactions. To fully characterize a real system undergoing one, often unsteady, work interaction, at least two intensive properties are needed, the limit of which is the thermodynamic simple system. At steady state, the simple system reduces to the singlevariable system described in Equation (A1). For example, the accuracy of Coulomb-counted charge capacity is directly dependent on the rechargeable battery's cycling rate-higher accuracy for slow cycling with minimal temperature rise [52-56].

For real systems undergoing nonequilibrium transformations, Prigogine defined the variation of entropy production $[46,48]$

$$
\dot{S}_{\text {local }}^{\prime}=\frac{J \dot{X}}{T}+\frac{X \dot{J}}{T}
$$


where the first right-hand side term characterizes internal instabilities. Combining the first and second laws of thermodynamics with the free energies, Osara and Bryant showed that a (thermodynamic) system's free entropy generation rate [2,27-30]

$$
\dot{S}^{\prime}=\frac{-S \dot{T}}{T}+\frac{X \dot{J}}{T}-\frac{\dot{A}_{r e v}}{T}
$$

where $\mathrm{S}$ is entropy content, $A_{\text {rev }}$ is the free energy (Helmholtz or Gibbs) and other variables are as defined previously. Equation (A3) applies to all real macroscopic systems undergoing far-from-equilibrium energy transformations. The last right-hand side term in Equation (A3), the reversible entropy rate, can be assumed constant and defined at an initial/final reference time, and can be neglected in active system analysis. The first two right-hand side terms form the phenomenological entropy generation rate [2,27-30]

$$
\dot{S}_{\text {phen }}^{\prime}=\frac{-S \dot{T}}{T}+\frac{X \dot{J}}{T}
$$

which measures a real system's instantaneous maximum work-based entropy generation rate [2,27-30]. In Equations (A3) and (A4), the first right-hand side term measures the internal dissipation effects and fluctuations that accompany unsteady processes, and the second term is the primary interaction entropy (used throughout the main article) that defines minimum entropy generation. Hence, for highly transient interactions, the minimum entropy generation, Equation (A1), is inadequate; Equations (A2)-(A4) are recommended instead. For a pseudo steady-state process or a process with minimal temperature variation $(\dot{T} \approx 0)$ or a quasi-static - approximating a very slow-process, Equations (A2) and (A4) reduce to Equation (A1), making the latter adequate for characterizing such processes. Significantly unsteady interactions are beyond the scope of this article, hence, for more on Equations (A1) and (A2), the interested reader should consult references [46,47]. Detailed derivations and discussions of Equations (A3) and (A4) can be found in references [2,27-30].

\section{References}

1. Bryant, M.D.; Khonsari, M.M.; Ling, F.F. On the thermodynamics of degradation. Proc. R. Soc. A Math. Phys. Eng. Sci. 2008, 2001-2014. [CrossRef]

2. Osara, J.A. Thermodynamics of Degradation; The University of Texas at Austin: Austin, TX, USA, 2017. [CrossRef]

3. Basaran, C.; Nie, S. An irreversible thermodynamics theory for damage mechanics of solids. Int. J. Damage Mech. 2004, 13, 205-223. [CrossRef]

4. Basaran, C.; Lin, M.; Ye, H. A thermodynamic model for electrical current induced damage. Int. J. Solids Struct. 2003, 40, 7315-7327. [CrossRef]

5. Basaran, C.; Yan, C.Y. A Thermodynamic Framework for Damage Mechanics of Solder Joints. ASME Trans. J. Electron. Packag. 1998, 120, 379-384. [CrossRef]

6. Gomez, J.; Basaran, C. Damage mechanics constitutive model for $\mathrm{Pb} / \mathrm{Sn}$ solder joints incorporating nonlinear kinematic hardening and rate dependent effects using a return mapping integration algorithm. Mech. Mater. 2006, 38, 585-598. [CrossRef]

7. Gomez, J.; Basaran, C. A thermodynamics based damage mechanics constitutive model for low cycle fatigue analysis of microelectronics solder joints incorporating size effects. Int. J. Solids Struct. 2005, 42, 3744-3772. [CrossRef]

8. Basaran, C. Introduction to Unified Mechanics Theory with Applications, 1st ed.; Springer International Publishing: Berlin/Heidelberg, Germany, 2021. [CrossRef]

9. Sosnovskiy, L.A.; Sherbakov, S.S. On the development of mechanothermodynamics as a new branch of Physics. Entropy 2019, 21, 1188. [CrossRef]

10. Sosnovskiy, L.; Sherbakov, S. Mechanothermodynamic Entropy and Analysis of Damage State of Complex Systems. Entropy 2016, 18, 268. [CrossRef]

11. Naderi, M.; Khonsari, M. Real-time fatigue life monitoring based on thermodynamic entropy. Struct. Health Monit. 2011, 10, 189-197. [CrossRef]

12. Amiri, M.; Naderi, M.; Khonsari, M.M. An Experimental Approach to Evaluate the Critical Damage. Int. J. Damage Mech. 2011, 20, 89-112. [CrossRef]

13. Naderi, M.; Khonsari, M.M. Thermodynamic analysis of fatigue failure in a composite laminate. Mech. Mater. 2012, 46, 113-122. [CrossRef] 
14. Amiri, M.; Khonsari, M.M. Rapid determination of fatigue failure based on temperature evolution: Fully reversed bending load. Int. J. Fatigue 2010, 32, 382-389. [CrossRef]

15. Naderi, M.; Khonsari, M.M. An experimental approach to low-cycle fatigue damage based on thermodynamic entropy. Int. J. Solids Struct. 2010, 47, 875-880. [CrossRef]

16. Naderi, M.; Amiri, M.; Khonsari, M.M. On the thermodynamic entropy of fatigue fracture. Proc. R. Soc. A Math. Phys. Eng. Sci. 2010, 46, 423-438. [CrossRef]

17. Naderi, M.; Khonsari, M.M. A comprehensive fatigue failure criterion based on thermodynamic approach. J. Compos. Mater. 2012, 46, 437-447. [CrossRef]

18. Lijesh, K.P.; Khonsari, M.M. Characterization of abrasive wear using degradation coefficient. Wear 2020, 450-451, 203220. [CrossRef]

19. Lijesh, K.P.; Khonsari, M.M. Characterization of multiple wear mechanisms through entropy. Tribol. Int. 2020, 152, 106548. [CrossRef]

20. Rezasoltani, A.; Khonsari, M.M. On the correlation between mechanical degradation of lubricating grease and entropy. Tribol. Lett. 2014, 56, 197-204. [CrossRef]

21. Cuadras, A.; Crisóstomo, J.V.; Ovejas, J.; Quilez, M. Irreversible entropy model for damage diagnosis in resistors. J. Appl. Phys. 2015, 118, 165103. [CrossRef]

22. Cuadras, A.; Romero, R.; Ovejas, V.J. Entropy characterisation of overstressed capacitors for lifetime prediction. J. Power Sources 2016, 336, 272-278. [CrossRef]

23. Cuadras, A.; Miró, P.; Ovejas, V.J.; Estrany, F. Entropy generation model to estimate battery ageing. J. Energy Storage 2020, 32, 101740. [CrossRef]

24. Doelling, K.L.; Ling, F.F.; Bryant, M.D.; Heilman, B.P. An experimental study of the correlation between wear and entropy flow in machinery components. J. Appl. Phys. 2000, 88, 2999-3003. [CrossRef]

25. Ling, F.F.; Bryant, M.D.; Doelling, K.L. On irreversible thermodynamics for wear prediction. Wear 2002, 253, 1165-1172. [CrossRef]

26. Bryant, M.D. Entropy and Dissipative Processes of Friction and Wear. FME Trans. 2009, 37, 55-60.

27. Osara, J.A.; Bryant, M.D. Thermodynamics of grease degradation. Tribol. Int. 2019, 137, 433-445. [CrossRef]

28. Osara, J.A.; Bryant, M.D. A Thermodynamic Model for Lithium-Ion Battery Degradation: Application of the Degradation-Entropy Generation Theorem. Inventions 2019, 2, 23. [CrossRef]

29. Osara, J.; Bryant, M. Thermodynamics of Fatigue: Degradation-Entropy Generation Methodology for System and Process Characterization and Failure Analysis. Entropy 2019, 21, 685. [CrossRef]

30. Osara, J.A.; Bryant, M.D. Thermodynamics of Lead-Acid Battery Degradation: Application of the Degradation-Entropy Generation Methodology. J. Electrochem. Soc. 2019, 166, A4188. [CrossRef]

31. ASTM, D. Standard Test Methods for Cone Penetration of Lubricating Grease Using One-Quarter. ASTM Int. $2003,5,1-9$.

32. Lugt, P.M. Lubricating Grease Rheology. In Grease Lubrication in Rolling Bearings; John Wiley \& Sons, Ltd.: Hoboken, NJ, USA, 2013; pp. 99-136.

33. Cyriac, F.; Lugt, P.M.; Bosman, R. On a New Method to Determine the Yield Stress in Lubricating Grease. Tribol. Trans. 2015, 58, 1021-1030. [CrossRef]

34. Yeong, S.K.; Luckham, P.F.; Tadros, T.F. Steady flow and viscoelastic properties of lubricating grease containing various thickener concentrations. J. Colloid Interface Sci. 2004, 274, 285-293. [CrossRef]

35. Sisko, A.W. The Flow of Lubricating Greases. Ind. Eng. Chem. 1958, 50, 1789-1792. [CrossRef]

36. Meyers, M.A.; Chawla, K.K. Mechanical Behavior of Materials; Cambridge University Press: London, UK, 2009.

37. Gecim, B.; Winer, W.O. Lubricant limiting shear stress effect on EHD film thickness. J. Lubr. Technol. 1980, 102, 213-220. [CrossRef]

38. Barnes, H.A. Thixotropy-A review. J. Nonnewton. Fluid Mech. 1997, 70, 1-33. [CrossRef]

39. Cross, M.M. Rheology of non-Newtonian fluids: A new flow equation for pseudoplastic systems. J. Colloid Sci. 1965, $20,417-437$. [CrossRef]

40. Rhee, I.-S. Decomposition Kinetics of Greases by Thermal Analysis; DTIC Document; Tacom Research Development and Engineering Center: Warren, MI, USA, 2007.

41. Lugt, P.M.; Pallister, D.M. Grease Aging. In Grease Lubrication in Rolling Bearings; Wiley: Hoboken, NJ, USA, 2013 ; pp. 171-190.

42. Walsh, F.C.; Reade, G.W. Industrial Electrochemistry, 2nd ed.; Chapman and Hall: London, UK, 1990.

43. Richard, G.; Budynas, J.K. Nisbett, Shigley's Mechanical Engineering Design; McGraw-Hill: New York, NY, USA, 2015.

44. Morrow, J. Cyclic Plastic Strain Energy and Fatigue of Metals. ASTM Int. 1965. [CrossRef]

45. Duyi, Y.; Zhenlin, W. A new approach to low-cycle fatigue damage based on exhaustion of static toughness and dissipation of cyclic plastic strain energy during fatigue. Int. J. Fatigue 2001, 23, 679-687. [CrossRef]

46. Prigogine, I. Introduction to Thermodynamics of Irreversible Processes. J. Electrochem. Soc. 1955. [CrossRef]

47. Kondepudi, D.; Prigogine, I. Modern Thermodynamics: From Heat Engines to Dissipative Structures; John Wiley \& Sons Ltd.: Hoboken, NJ, USA, 1998.

48. Glansdorff, P.; Prigogine, I. Thermodynamic Theory of Structure, Stability and Fluctuations; John Wiley \& Sons Ltd.: Hoboken, NJ, USA, 1971.

49. Moran, M.J.; Shapiro, H.N. Fundamentals of Engineering Thermodynamics, 5th ed.; Wiley: Hoboken, NJ, USA, 2004. 
50. De Groot, S.R. Thermodynamics of Irreversible Processes; North-Holland Publishing Company: Amsterdam, The Netherlands, 1951. [CrossRef]

51. Callen, H.B. Thermodynamics and an Introduction to Thermostatistics; John Wiley \& Sons, Ltd.: Hoboken, NJ, USA, 1985.

52. Rahn, C.D.; Wang, C.-Y. Battery Systems Engineering; John Wiley \& Sons Ltd.: Hoboken, NJ, USA, 2013. [CrossRef]

53. Rand, D.A.J.; Moseley, P.T. Energy Storage with Lead-Acid Batteries; Elsevier B.V.: Amsterdam, The Netherlands, 2015. [CrossRef]

54. Scrosati, B.; Garche, J. Lithium batteries: Status, prospects and future. J. Power Sources 2010, 195, 2419-2430. [CrossRef]

55. Vetter, J.; Novák, P.; Wagner, M.R.; Veit, C.; Möller, K.C.; Besenhard, J.O.; Winter, M.; Wohlfahrt-Mehrens, M.; Vogler, C.; Hammouche, A. Ageing mechanisms in lithium-ion batteries. J. Power Sources 2005, 147, 269-281. [CrossRef]

56. Huggins, R.A. Energy Storage, 2nd ed.; Springer: Berlin/Heidelberg, Germany, 2010. [CrossRef] 